\title{
Adverse pregnancy outcomes in women with high pre-pregnancy body mass index ${ }^{*}$
}

\author{
Rajin Arora $^{1 \#}$, Darin Arora ${ }^{1}$, Jayanton Patumanond ${ }^{2}$ \\ ${ }^{1}$ Department of Obstetrics and Gynecology, Lampang Regional Hospital, Lampang, Thailand \\ ${ }^{2}$ Clinical Epidemiology Unit, Chiang Mai University, Chiang Mai, Thailand \\ Email: ${ }^{*}$ rajin@cpird.in.th
}

Received 28 December 2012; revised 30 January 2013; accepted 10 February 2013

\begin{abstract}
Background/Aims: Obesity along with high prepregnancy body mass index (PP-BMI) is known to cause many adverse pregnancy outcomes. In Thailand, there is not much study showing both the prevalence and complications of these conditions. The objectives of this study were to estimate the prevalence of pre-pregnancy overweight and obesity and their impacts on adverse pregnancy outcomes. Methods: This study was a cross sectional study. Data were collected retrospectively from hospital electronic database along with manual retrieval from medical charts and labor records. Data of all delivery women from $1^{\text {st }}$ February 2011 to $31^{\text {st }}$ August 2012 were collected. When excluded cases with incomplete data and those without PP-BMI, 5420 cases were into analysis. Descriptive and inferential data analyses were used with both univariate and multivariate methods. Results: The proportion of pregnant women with overweight and obesity were $11.1 \%$ and $3.9 \%$. After multiple logistic regression analysis was done, women in obesity group were correlated with having 1, 2 and 3 complications. They were also correlated with preeclampsia, gestational diabetes, cesarean section, higher birth weight group and long neonatal length. Conclusions: This Thai prevalence of obesity in pregnancy should alarm health care providers to be more prepared, for a future health problem of the country. Many complications that come with obese pregnant women that were reported in western countries also happen in Thai population. Decreasing body weight before conception, giving correct health education, well planned pregnancy; antenatal lifestyle intervention and even gestational weight gain restricttion could help avoiding these uneventful morbidities.
\end{abstract}

Keywords: Pre-Pregnancy; Body Mass Index; Obesity;

*Disclosure: There is no financial or commercial conflict of interest. This paper was granted by Research Committee of Lampang Regional Hospital.

\#Corresponding author.
Pregnancy; Prevalence; Pregnancy Outcome

\section{INTRODUCTION}

In 2009, World Health Organization (WHO) announced obesity in pregnancy as one of the important non-communicable diseases that threaten maternal and child health [1]. The European Forum of National Nursing and Midwifery Associations also recognized this growing problem. And it established the roles of health care personnel in early detection and giving interventions to prevent complications from high pre-pregnancy body mass index (PP-BMI) and obesity [2].

The prevalence of obesity in pregnancy has been increasing along with the prevalence of obesity in general population $[3,4]$. Generally, the reported prevalence was about $4.7 \%-38 \%$ [3-12]. So far, there is no definite prevalence report of Thai pregnant women. From a preliminary survey at Lampang Regional Hospital (LPH) in $2010,14.9 \%$ of new cases at antenatal clinic were overweight and $7.2 \%$ were obese. There was a report from another Thai hospital showed that the prevalence of overweight was $13 \%$ and obesity was only $4 \%$ [13].

Obesity along with high PP-BMI is also known to cause many complications ranging from increased risks of infertility, hypertensive disorders, gestational diabetes mellitus, pregnancy-related pelvic pain, preterm labor, postterm, obstructed labor, intrauterine fetal death, stillbirth, operative obstetrics procedure and cesarean section $[3,6,10-12,14-27]$. The above risks were reported to be higher in the super-obese women $\left(\mathrm{BMI} \geq 50 \mathrm{~kg} / \mathrm{m}^{2}\right)$ [28]. Moreover, there are reports stating that obesity also increased minor complications in pregnancy and caused additional costs from using more frequent health care services [29-31].

In Thailand, there is not much study showing the relation of adverse outcomes of obesity and high PP-BMI in pregnant women. There were 2 quality studies so far, but conclusion could not be drawn. The first study reported the correlation of obesity only with higher cesarean 
delivery, pregnancy-induced hypertension and large for gestational age [32]. Another study in 2011 showed that overweight and obesity resulted in significant risk of cesarean section, preeclampsia, diabetes mellitus and postpartum hemorrhage. But no correlation was found between PP-BMI to stillbirth and congenital anomaly [13].

The first objective of this study was to estimate the prevalence of pre-pregnancy overweight and obesity in pregnant women at LPH. The second objective was to identify the increased proportion of adverse pregnancy outcomes in these groups of women. LPH is one of the regional hospitals of Ministry of Public Health in northern Thailand. With the capacity of 800 beds and many excellent centers contained, it very well represents a tertiary care hospital of the country.

\section{MATERIALS AND METHODS}

\subsection{Samples}

This study was a cross sectional study. Data were collected retrospectively from hospital electronic database of LPH along with manual retrieval from medical charts and labor records. Data of all pregnant women who delivered at labor room LPH were collected from $1^{\text {st }}$ February 2011 to $31^{\text {st }}$ August 2012. There were 5640 cases that were delivered in this period. When excluded cases with incomplete data and those without PP-BMI, 5420 cases were left for analysis. The study flow is shown as Figure 1.

\subsection{Data Collection}

Before 2011, maternal pre-pregnancy weight data were not complete. But from 2011, health care personnel of LPH were encouraged to document pre-pregnancy weight and height data of every pregnant woman from her first antenatal care visit. Data collection of this study were pre-pregnancy weight, height and BMI along with demographic, obstetric and pregnancy outcomes of both mother and child. This research had been endorsed by Ethics Committee of Lampang Regional Hospital.

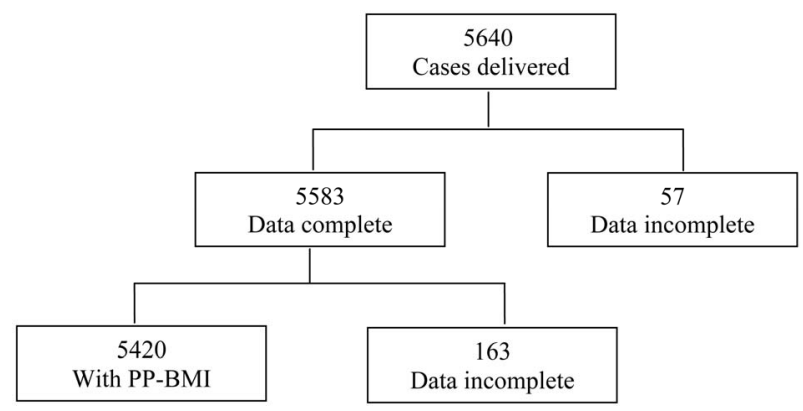

Figure 1. Number of cases delivered and number of illegible cases.

\subsection{Categorization of BMI}

This study used the definition of The National Heart, Lung and Blood Institute in 1998 to classify pre-pregnancy BMI [33]. Nevertheless, low BMI group was also supplemental defined for the analysis as pre-pregnancy $\mathrm{BMI}<18.5 \mathrm{~kg} / \mathrm{m}^{2}$. The 4 PP-BMI groups were

1) Low BMI: BMI $<18.5 \mathrm{~kg} / \mathrm{m}^{2}$;

2) Normal BMI: BMI $18.5-24.9 \mathrm{~kg} / \mathrm{m}^{2}$;

3) Overweight: BMI $25-29.9 \mathrm{~kg} / \mathrm{m}^{2}$;

4) Obesity: $\mathrm{BMI} \geq 30 \mathrm{~kg} / \mathrm{m}^{2}$.

\subsection{Analysis Procedure}

In the analysis, the proportions of pregnant women with each group of PP-BMI were calculated. Demographic, obstetric, complications in pregnancy and pregnancy outcomes of both mother and child were compared among 4 groups of PP-BMI. The interested variables were maternal age, maternal height, gravidity, private delivery case, frequency of antenatal care (ANC), health benefit scheme, places of ANC, HIV infection, $1^{\text {st }}$ and $2^{\text {nd }}$ hemoglobin test, complication in pregnancy, gestational age, mode of delivery, presentation, neonatal sex, birth weight, neonatal length and Apgar score.

Data were analyzed in a retrospective cohort approach using standard statistical software. Fisher's exact probability test and student t-test were used where applicable for univariate analysis. Then multivariate analysis was deployed to control the confounders and retrieve the final correlation.

\section{RESULTS}

Within these 19 months period, there were 5420 delivery women with complete data of PP-BMI and interesting variables. All cases were delivered at Lampang Regional Hospital. Table 1 shows the proportion of pregnant women with different PP-BMI. There were $11.1 \%$ and 3.9\% of cases who were overweight and obese before pregnancy respectively.

Table 1 also shows all demographic and obstetric factors. While Table 2 shows the complications in pregnancy. The variables were analyzed by comparing among 4 groups of PP-BMI. Univariate analysis showed that overweight and obesity group had significantly more women with elderly pregnancy. Mean maternal age of overweight and obese group were also significantly higher than the other 2 groups. Proportions of short maternal stature (height $<145 \mathrm{~cm}$ ) were comparable among 4 groups of PP-BMI.

The proportions of nulliparous women in overweight and obesity group were significantly much lower than the other 2 groups. The proportions of private delivery case were significantly lower in overweight and obesity group too. Regarding health scheme benefit, overweight 
Table 1. Demographic and obstetric characteristics of women classified into 4 pre-pregnancy BMI groups.

\begin{tabular}{|c|c|c|c|c|c|}
\hline Characteristics & $\begin{array}{c}\text { Low BMI } \\
\begin{array}{c}(\mathrm{n}=1020) \\
\mathrm{n}(\%)\end{array}\end{array}$ & $\begin{array}{l}\text { Normal BMI } \\
\qquad \begin{array}{c}(\mathrm{n}=3433) \\
\mathrm{n}(\%)\end{array}\end{array}$ & $\begin{array}{l}\text { Overweight } \\
\begin{array}{c}(\mathrm{n}=583) \\
\mathrm{n}(\%)\end{array}\end{array}$ & $\begin{array}{c}\text { Obesity } \\
(\mathrm{n}=204) \\
\mathrm{n}(\%)\end{array}$ & P-value \\
\hline BMI range $\left(\mathrm{kg} / \mathrm{m}^{2}\right)$ & $<18.5$ & $18.5-24.9$ & $25.0-29.9$ & $\geq 30.0$ & - \\
\hline Prevalence (\%) & 19.5 & 66.5 & 11.1 & 3.9 & - \\
\hline \multicolumn{6}{|l|}{ Maternal age group (year) } \\
\hline$<20$ & $232(22.8)$ & $458(13.3)$ & $32(5.5)$ & $16(7.8)$ & $<0.001$ \\
\hline $20-34$ & $736(72.2)$ & $2541(74.0)$ & $449(77.0)$ & $154(75.5)$ & \\
\hline$\geq 35$ & $52(5.1)$ & $434(12.6)$ & $102(17.5)$ & $34(16.7)$ & \\
\hline Mean \pm SD & $24.4 \pm 5.7$ & $27.0 \pm 6.3$ & $28.9 \pm 6.1$ & $28.5 \pm 6.2$ & $<0.001$ \\
\hline Short stature $(<145 \mathrm{~cm})$ & $9(0.9)$ & $71(2.1)$ & $11(1.9)$ & $2(1.0)$ & 0.057 \\
\hline Nulliparous & $619(60.7)$ & $1600(46.6)$ & $194(33.3)$ & $64(31.4)$ & $<0.001$ \\
\hline Twins pregnancy & $10(1.0)$ & $29(0.8)$ & $3(0.5)$ & $0(0.0)$ & 0.547 \\
\hline Private delivery case & $425(41.7)$ & $1511(44.0)$ & $229(39.3)$ & $71(34.8)$ & 0.012 \\
\hline No ANC & $26(2.6)$ & $57(1.7)$ & $9(1.5)$ & $4(2.0)$ & 0.182 \\
\hline Universal coverage & $474(46.5)$ & $1429(41.6)$ & $279(47.9)$ & $112(54.9)$ & 0.007 \\
\hline Private ANC only & $297(29.1)$ & $1115(32.5)$ & $189(32.4)$ & $52(25.5)$ & 0.140 \\
\hline HIV & $7(0.7)$ & $26(0.8)$ & $8(1.4)$ & $2(1.0)$ & 0.327 \\
\hline \multicolumn{6}{|l|}{ Anemia } \\
\hline First $\mathrm{Hb}$ test & $234(23.3)$ & $581(17.1)$ & $58(10.1)$ & $13(6.5)$ & $<0.001$ \\
\hline Second $\mathrm{Hb}$ test & $123(18.9)$ & $356(16.5)$ & $50(13.0)$ & $12(8.4)$ & 0.004 \\
\hline
\end{tabular}

Table 2. Complications during pregnancy in women classified into 4 pre-pregnancy BMI groups.

\begin{tabular}{|c|c|c|c|c|c|}
\hline Complications & $\begin{array}{c}\text { Low BMI } \\
\text { n (\%) }\end{array}$ & $\begin{array}{c}\text { Normal BMI } \\
\mathrm{n}(\%)\end{array}$ & $\begin{array}{c}\text { Overweight } \\
\text { n (\%) }\end{array}$ & $\begin{array}{c}\text { Obesity } \\
\text { n (\%) }\end{array}$ & P-value \\
\hline \multicolumn{6}{|l|}{ Items } \\
\hline 1 & $470(46.1)$ & $1502(43.8)$ & $297(51.0)$ & $106(52.0)$ & 0.002 \\
\hline 2 & $123(12.1)$ & $503(14.6)$ & $112(19.2)$ & 40 (19.6) & $<0.001$ \\
\hline 3 & $27(2.6)$ & $137(4.0)$ & $37(6.4)$ & $11(5.4)$ & 0.003 \\
\hline Preeclampsia & $12(1.2)$ & $85(2.5)$ & $35(6.0)$ & $19(9.3)$ & $<0.001$ \\
\hline Antepartum hemorrhage & $11(1.1)$ & $34(1.0)$ & $6(1.0)$ & $1(0.5)$ & 0.942 \\
\hline Chorioamnionitis & $2(0.2)$ & $6(0.2)$ & $1(0.2)$ & $0(0.0)$ & 1.000 \\
\hline Gestational diabetes & $13(1.3)$ & $117(3.4)$ & $56(9.6)$ & $33(16.2)$ & $<0.001$ \\
\hline Postpartum hemorrhage & $7(0.7)$ & $42(1.2)$ & $5(0.9)$ & $2(1.0)$ & 0.541 \\
\hline PROM & $41(4.0)$ & $145(4.2)$ & $25(4.3)$ & $7(3.4)$ & 0.965 \\
\hline
\end{tabular}

and obesity group had significantly higher proportions of women with universal coverage scheme. Nevertheless, these 4 groups of PP-BMI did not have significant difference of proportions of women having twins pregnancy, no antenatal care (ANC), private ANC only and HIV infection.

The overweight and obesity group significantly had lower proportion of women with anemia from both routine Hemoglobin 1 (Hb1) and Hemoglobin 2 ( $\mathrm{Hb} 2)$ test. In this set of data the results of $1^{\text {st }}$ routine and $2^{\text {nd }}$ riskbased VDRL test were all negative. Regarding complication in pregnancy, overweight and obesity group significantly had higher proportions of women having 1,2 and
3 complications. Further analysis of these complications showed that overweight and obesity group significantly had higher proportions of women with preeclampsia and gestational diabetes but not with Antepartum hemorrhage, chorioamnionitis, postpartum hemorrhage and premature rupture of membrane.

Table 3 shows the results of univariate analysis of pregnancy outcomes. These 4 groups of PP-BMI had comparable proportions of women with preterm and postterm birth. Regarding mode of delivery, overweight and obesity group had significantly more women who delivered by cesarean section (CS). These 2 groups also had significantly more women with indications of previous 
Table 3. Outcomes of pregnancy in women classified into 4 pre-pregnant BMI groups.

\begin{tabular}{|c|c|c|c|c|c|}
\hline Outcomes of pregnancy & $\begin{array}{c}\text { Low BMI } \\
\text { n (\%) }\end{array}$ & $\begin{array}{c}\text { Normal BMI } \\
\text { n (\%) }\end{array}$ & $\begin{array}{c}\text { Overweight } \\
\text { n (\%) }\end{array}$ & $\begin{array}{c}\text { Obesity } \\
\text { n (\%) }\end{array}$ & P-value \\
\hline \multicolumn{6}{|l|}{ Gestation (week) } \\
\hline$<37$ & $108(10.6)$ & $304(8.8)$ & $48(8.2)$ & $16(7.8)$ & 0.069 \\
\hline $37-41$ & 905 (88.7) & $3110(90.6)$ & $530(90.9)$ & 187 (91.7) & \\
\hline$\geq 42$ & $7(0.7)$ & $19(0.6)$ & $5(0.9)$ & $1(0.5)$ & \\
\hline Cesarean section & $276(26.8)$ & $1316(38.0)$ & $274(46.8)$ & $127(62.2)$ & $<0.001$ \\
\hline \multicolumn{6}{|l|}{ Indications } \\
\hline Previous CS & $45(16.3)$ & $324(24.6)$ & $97(35.4)$ & $36(28.4)$ & $<0.001$ \\
\hline CPD & $130(47.1)$ & $597(45.4)$ & $105(38.3)$ & $65(51.2)$ & \\
\hline Fetal distress & $23(8.3)$ & $80(6.1)$ & $12(4.4)$ & $9(7.1)$ & \\
\hline Vertex presentation & 997 (96.9) & 3317 (95.9) & $563(96.2)$ & $196(96.1)$ & 0.426 \\
\hline Male neonate & $553(53.7)$ & $1846(53.3)$ & $310(52.9)$ & $113(55.4)$ & 0.933 \\
\hline \multicolumn{6}{|l|}{ Birth weight (g) } \\
\hline$<2500$ & $166(16.2)$ & $356(10.3)$ & $38(6.5)$ & $13(6.4)$ & $<0.001$ \\
\hline $2501-3499$ & $784(76.3)$ & $2605(75.4)$ & $410(70.4)$ & $123(60.6)$ & \\
\hline$\geq 3500$ & $78(7.6)$ & $496(14.4)$ & $134(23.0)$ & $67(33.0)$ & \\
\hline Mean $\pm \mathrm{SD}$ & $2883.5 \pm 478.2$ & $3030.5 \pm 467.3$ & $3138.4 \pm 481.8$ & $3292.5 \pm 547.3$ & $<0.001$ \\
\hline Long neonate & $108(10.5)$ & $523(15.1)$ & 115 (19.6) & $53(26.0)$ & $<0.001$ \\
\hline \multicolumn{6}{|l|}{ Placental weight (g) } \\
\hline Mean $\pm \mathrm{SD}$ & $261.0 \pm 96.9$ & $254.4 \pm 100.9$ & $259.4 \pm 121.7$ & $256.2 \pm 141.4$ & 0.304 \\
\hline \multicolumn{6}{|l|}{ Apgar score 0 - 3} \\
\hline At 1 minute & $7(0.7)$ & $21(0.6)$ & $6(1.0)$ & $1(0.5)$ & 0.861 \\
\hline At 5 minute & $3(0.3)$ & $5(0.1)$ & $5(0.8)$ & $0(0.0)$ & 0.047 \\
\hline At 10 minute & $3(0.3)$ & $4(0.1)$ & $2(0.3)$ & $0(0.0)$ & 0.408 \\
\hline
\end{tabular}

cesarean and cephalopelvic disproportion (CPD), while the indication of fetal distress were comparable among 4 groups of PP-BMI. The proportions of vertex presentation and male neonate were comparable among these 4 groups of PP-BMI.

Overweight and obesity group had significantly higher proportions of neonates with birth weight $\geq 3500 \mathrm{gm}$. Accordingly, these 2 groups also had significantly lower proportions of neonates with birth weight $<2500 \mathrm{gm}$. These effects were also showed when comparing mean birth weight of these 4 PP-BMI groups and found that overweight and obesity group had significantly higher mean birth weight than the other 2 groups. With mean of neonatal length of 49.6 and SD of 2.2, neonatal length was categorized as long neonatal length when it was $\geq 52$ $\mathrm{cm}$. Overweight and obesity group had significantly higher proportion of neonates with long neonatal length. But these 4 groups had comparable mean placental weight. Regarding severe birth asphyxia, though proportions of neonate with Apgar score $0-3$ at 1,5 and 10 minute were comparable; it showed statistically significant difference of Apgar score 0 - 3 at 5 minute.

After univariate analysis was done for every interesting variable, multiple logistic regression analysis was used in multivariate analysis to control confounders. The results are shown in Table 4. Women in overweight and obesity groups were still correlated with having 1 and 2 complications. While having 3 complications was only correlated with obesity group with high relative risk (RR) and $95 \%$ confidence interval $(95 \% \mathrm{CI})$ of 4.10 (3.55 4.72). Preeclampsia and gestational diabetes were still shown to be correlated with both overweight and obesity groups with RR in obesity groups of 6.17 (2.74 - 13.93) and $7.34(4.07-13.26)$ respectively.

Higher gestational age group was shown to be significantly correlated with only overweight PP-BMI group with RR of 1.51 (1.09 - 2.09) but not with obesity group. Cesarean section and higher birth weight group were significantly correlated with both overweight and obesity group with RR for obesity group were 4.69 (3.39 - 6.47) and 4.14 (3.20 - 5.36) respectively. Long neonatal length was also shown to be significantly correlated with both overweight and obesity group with RR for obesity group was $2.58(1.60-4.18)$.

\section{DISCUSSION}

This study showed the prevalence of pre-pregnancy overweight and obesity at $11.1 \%$ and $3.9 \%$ respectively. This is lower than general reported prevalence from 
Table 4. Outcomes of pregnancy significantly affected by pre-delivery overweight and obesity (in multivariable analysis).

\begin{tabular}{|c|c|c|c|}
\hline Outcomes of pregnancy & Risk ratio $^{*}$ & $95 \%$ confidence interval & P-value \\
\hline \multicolumn{4}{|l|}{ Having 1 complication } \\
\hline Overweight & 1.43 & $1.06-1.92$ & 0.018 \\
\hline Obesity & 1.45 & $1.26-1.68$ & $<0.001$ \\
\hline \multicolumn{4}{|l|}{ Having 2 complications } \\
\hline Overweight & 1.54 & $1.31-1.82$ & $<0.001$ \\
\hline Obesity & 1.74 & $1.50-2.04$ & $<0.001$ \\
\hline \multicolumn{4}{|l|}{ Having 3 complications } \\
\hline Obesity & 4.10 & $3.55-4.72$ & $<0.001$ \\
\hline \multicolumn{4}{|l|}{ Preeclampsia } \\
\hline Overweight & 4.90 & $2.23-10.78$ & $<0.001$ \\
\hline Obesity & 6.17 & $2.74-13.93$ & $<0.001$ \\
\hline \multicolumn{4}{|l|}{ Gestational diabetes } \\
\hline Overweight & 4.16 & $2.28-7.58$ & $<0.001$ \\
\hline Obesity & 7.34 & $4.07-13.26$ & $<0.001$ \\
\hline \multicolumn{4}{|c|}{ Higher gestational age group } \\
\hline Overweight & 1.51 & $1.09-2.09$ & 0.013 \\
\hline \multicolumn{4}{|l|}{ Cesarean section } \\
\hline Overweight & 2.31 & $1.85-2.90$ & $<0.001$ \\
\hline Obesity & 4.69 & $3.39-6.47$ & $<0.001$ \\
\hline \multicolumn{4}{|l|}{ Higher birth weight group } \\
\hline Overweight & 2.88 & $2.37-3.52$ & $<0.001$ \\
\hline Obesity & 4.14 & $3.20-5.36$ & $<0.001$ \\
\hline \multicolumn{4}{|l|}{ Long neonatal length } \\
\hline Overweight & 1.69 & $1.26-2.25$ & $<0.001$ \\
\hline Obesity & 2.58 & $1.60-4.18$ & $<0.001$ \\
\hline
\end{tabular}

*From exponential risk (risk ratio) regression adjusted for significant predictors.

aboard at $4.7 \%$ - 38\% but comparable with a Thai study that showed the prevalence of overweight at $13 \%$ and obesity at 4\% [3-13]. This may be due to ethnic and life style different. Knowing that obesity prevalence in Thai population is still low, should not prohibit Thai health care personnel from good public health policies to decrease obesity in reproductive age women.

The second objective of this study showed that prepregnancy overweight and obesity posed many morbidities to both mother and child. This concurs with many studies reported before [3,6,10-27]. Women with overweight and obesity were correlated with having more items of complication comparing to normal and low prepregnancy BMI. This is especially true for obesity strongly correlated with having 3 items of complication. As previously shown in other studies from Thailand and aboard, preeclampsia and gestational diabetes were all shown here to be correlated with both overweight and obesity groups with RR in obesity groups as high as 6.17 (2.74 - 13.93) and $7.34(4.07-13.26)$ respectively.

Though gestational age in this study was shown to be marginally significant from univariate analysis, it was brought into multiple logistic regression analysis. Higher gestational age group was finally shown to be significantly correlated with overweight group but not with obesity group, with RR of only $1.51(1.09-2.09)$. This also concurs with some studies that gestational age was not affected by obesity in pregnancy [6,10,11,21]. Cesarean section and high birth weight had always been shown from other studies to be correlated with overweight and obesity $[6,10,12,13,21]$. These were also shown here with RR for obesity group at 4.69 (3.39 $6.47)$ and 4.14 (3.20 - 5.36) respectively.

This study posed an interesting finding regarding neonatal length. Long neonatal length was shown to be significantly correlated with both overweight and obesity with RR for obesity group was $2.58(1.60-4.18)$. This should prompt future studies to focus more on body structures of neonates of obese mothers. There are also morbidities that usually reported from other studies but not shown in this study e.g. postpartum hemorrhage, stillbirth and congenital anomaly. Only postpartum hemorrhage (PPH) that had been studied here, but the analysis showed comparable proportions of PPH among 4 
groups of PP-BMI. When comparing with the result from a Thai study that showed PPH as a significant complication of obesity, its prevalence of PPH in every group of PP-BMI was much higher than this study [13]. The no correlation finding in this study might be from this low prevalence of the event.

\section{CONCLUSIONS}

Ultimately, this study has achieved its goals by producing 2 interesting results that should wake up obstetricians in Thailand. First, the prevalence of obesity in pregnancy should alarm health care providers to be more prepared, for this should be a future health problem of the country. As it has been proposed for sometimes that the criteria of overweight and obesity for Thais should be changed to BMI $23 \mathrm{~kg} / \mathrm{m}^{2}$ and BMI $25 \mathrm{~kg} / \mathrm{m}^{2}$ respectively. Future study should be done using these criteria, for it should increase the prevalence drastically.

The second result of this study added important knowledge for Thai obstetric society as well. It showed that there are many complications that come with obese pregnant women even for Thais. This should alert health care providers to prevent these adverse events either before or during pregnancy. Since obesity is a modifiable risk factor, decreasing body weight before conception, giving correct health education, well planned pregnancy, antenatal lifestyle intervention and even gestational weight gain restriction could help avoiding the uneventful morbidities [34-37].

Further research should be done focusing on the criteria of obesity adjusted for the increased pregnancy complications. Moreover, future studies should have more samples than this study and prospective data collection should be considered if uncommon pregnancy complications would be investigated.

\section{REFERENCES}

[1] World Health Organization (2012) ECOSOC high-level segment 2009. Discussion paper: Noncommunicable diseases, poverty and the development agenda.

http://www.who.int/nmh/publications/discussion_paper_n cd_en.pdf

[2] World Health Organization (2012) Ninth annual meeting of the European Forum of National Nursing and Midwifery Associations and WHO. Report on a WHO meeting March 2005.

http://www.euro.who.int/ data/assets/pdf file/0013/102 226/E86646.pdf

[3] Alexandra, P., Vassilios, B., Alexandra, V., George, K., Vassiliki, L. and Chryssa, B. (2011) Population-based trnds of pregnancy outcome in obese mothers: What has changed over 15 years. Obesity, 19, 1861-1865. doi:10.1038/oby.2010.317

[4] Kim, S.Y., Dietz, P.M., England, L., Morrow, B. and Cal- laghan, W.M. (2007) Trends in pre-pregnancy obesity in nine states, 1993-2003. Obesity, 15, 986-993.

doi:10.1038/oby.2007.621

[5] Persson, M., Pasupathy, D., Hanson, U., Westgren, M. and Norman, M. (2012) Pre-pregnancy body mass index and the risk of adverse outcome in type 1 diabetic pregnancies: A population-based cohort study. BMJ Open, 2, e000601. doi:10.1136/bmjopen-2011-000601

[6] Ovesen, P., Rasmussen, S. and Kesmodel, U. (2011) Effect of prepregnancy maternal overweight and obesity on pregnancy outcome. Obstetrics \& Gynecology, 118, 305312. doi:10.1097/AOG.0b013e3182245d49

[7] Lu, G.C., Rouse, D.J., DuBard, M., Cliver, S., Kimberlin, D. and Hauth, J.C. (2001) The effect of the increasing prevalence of maternal obesity on perinatal morbidity. American Journal of Obstetrics \& Gynecology, 185, 845849. doi:10.1067/mob.2001.117351

[8] Tsoi, E., Shaikh, H., Robinson, S. and Teoh, T.G. (2010) Obesity in pregnancy: A major healthcare issue. Postgraduate Medical Journal, 86, 617-623. doi:10.1136/pgmj.2010.098186

[9] Flegal, K.M., Carroll, M.D., Ogden, C.L. and Curtin, L.R. (2010) Prevalence and trends in obesity among US adults, 1999-2008. JAMA, 303, 235-241. doi:10.1001/jama.2009.2014

[10] Liu, X., Du, J., Wang, G., Chen, Z., Wang, W. and Xi, Q. (2011) Effect of pre-pregnancy body mass index on adverse pregnancy outcome in north of China. Archives of Gynecology and Obstetrics, 283, 65-70. doi:10.1007/s00404-009-1288-5

[11] Aviram, A., Hod, M. and Yogev, Y. (2011) Maternal obesity: Implications for pregnancy outcome and longterm risks-A link to maternal nutrition. International Journal of Gynecology \& Obstetrics, 115, S6-S10. doi:10.1016/S0020-7292(11)60004-0

[12] Athukorala, C., Rumbold, A.R., Willson, K.J. and Crowther, C.A. (2010) The risk of adverse pregnancy outcomes in women who are overweight or obese. BMC Pregnancy Childbirth, 10, 56. doi:10.1186/1471-2393-10-56

[13] Saereeporncharenkul, K. (2011) Correlation of BMI to pregnancy outcomes in Thai women delivered in Rajavithi Hospital. Journal of the Medical Association of Thailand, 94, S52-S58.

[14] Wolfe, H. (1998) High prepregnancy body-mass indexA maternal-fetal risk factor. The New England Journal of Medicine, 338, 191-192. doi:10.1056/NEJM199801153380310

[15] Cnattingius, S., Bergström, R., Lipworth, L. and Kramer, M.S. (1998) Prepregnancy weight and the risk of adverse pregnancy outcomes. The New England Journal of Medicine, 338, 147-152. doi:10.1056/NEJM199801153380302

[16] Djelantik, A.A., Kunst, A.E., van der Wal, M.F., Smit, H.A. and Vrijkotte, T.G. (2012) Contribution of overweight and obesity to the occurrence of adverse pregnancy outcomes in a multi-ethnic cohort: Population attributive fractions for Amsterdam. BJOG, 119, 283-290. doi:10.1111/j.1471-0528.2011.03205.x 
[17] Park, J.H., Lee, B.E., Park, H.S., Ha, E.H., Lee, S.W. and Kim, Y.J. (2011) Association between pre-pregnancy body mass index and socioeconomic status and impact on pregnancy outcomes in Korea. Journal of Obstetrics and Gynaecology Research, 37, 138-145. doi:10.1111/j.1447-0756.2010.01332.x

[18] Biering, K., Nøhr, E.A., Olsen, J., Andersen, A.M., Hjøllund, N.H. and Juhl, M. (2011) Pregnancy-related pelvic pain is more frequent in women with increased body mass index. Acta Obstetricia et Gynecologica Scandinavica, 90, 1132-1139. doi:10.1111/j.1600-0412.2011.01141.x

[19] Owens, L.A., O’Sullivan, E.P., Kirwan, B., Avalos, G., Gaffney, G., Dunne, F., et al. (2010) ATLANTIC DIP: The impact of obesity on pregnancy outcome in glucose-tolerant women. Diabetes Care, 33, 577-579. doi:10.2337/dc09-0911

[20] Narchi, H. and Skinner, A. (2010) Overweight and obesity in pregnancy do not adversely affect neonatal outcomes: New evidence. Journal of Obstetrics and Gynaecology, 30, 679-686. doi:10.3109/01443615.2010.509824

[21] Aydin, C., Baloglu, A., Yavuzcan, A. and Inci, A. (2010) The effect of body mass index value during labor on pregnancy outcomes in Turkish population (obesity and pregnancy outcomes). Archives of Gynecology and $\mathrm{Ob}$ stetrics, 281, 49-54. doi:10.1007/s00404-009-1060-X

[22] Yogev, Y. and Catalano, P.M. (2009) Pregnancy and obesity. Obstetrics \& Gynecology Clinics of North America, 36, 285-300. doi:10.1016/j.ogc.2009.03.003

[23] Smith, G.C., Shah, I., Pell, J.P., Crossley, J.A. and Dobbie, R. (2007) Maternal obesity in early pregnancy and risk of spontaneous and elective preterm deliveries: A retrospective cohort study. American Journal of Public Health, 97, 157-162. doi:10.2105/AJPH.2005.074294

[24] Bhattacharya, S., Campbell, D.M., Liston, W.A. and Bhattacharya S. (2007) Effect of body mass index on pregnancy outcomes in nulliparous women delivering singleton babies. BMC Public Health, 7, 168. doi:10.1186/1471-2458-7-168

[25] Yu, C.K., Teoh, T.G. and Robinson, S. (2006) Obesity in pregnancy. BJOG, 113, 1117-1125. doi:10.1111/j.1471-0528.2006.00991.x

[26] Raatikainen, K., Heiskanen, N. and Heinonen, S. (2006) Transition from overweight to obesity worsens pregnancy outcome in a BMI-dependent manner. Obesity, 14, 165171. doi:10.1038/oby.2006.20

[27] Doherty, D.A., Magann, E.F., Francis, J., Morrison, J.C. and Newnham, J.P. (2006) Pre-pregnancy body mass in- dex and pregnancy outcomes. International Journal of Gynecology \& Obstetrics, 95, 242-247.

doi:10.1016/i.ijgo.2006.06.021

[28] Alanis, M.C., Goodnight, W.H., Hill, E.G., Robinson, C.J., Villers, M.S. and Johnson, D.D. (2010) Maternal super-obesity (body mass index $>$ or $=50$ ) and adverse pregnancy outcomes. Acta Obstetricia et Gynecologica Scandinavica, 89, 924-930. doi:10.3109/00016341003657884

[29] Denison, F.C., Norrie, G., Graham, B., Lynch, J., Harper, N. and Reynolds, R.M. (2009) Increased maternal BMI is associated with an increased risk of minor complications during pregnancy with consequent cost implications. BJOG, 116, 1467-1472. doi:10.1111/j.1471-0528.2009.02222.x

[30] Chu, S.Y., Bachman, D.J., Callaghan, W.M., Whitlock, E.P., Dietz, P.M., Berg, C.J., et al. (2008) Association between obesity during pregnancy and increased use of health care. The New England Journal of Medicine, 358, 1444-1453. doi:10.1056/NEJMoa0706786

[31] Galtier-Dereure, F., Boegner, C. and Bringer, J. (2000) Obesity and pregnancy: Complications and cost. The American Journal of Clinical Nutrition, 71, 1242S-1248S.

[32] Rudtanasudjatum, K. and Chullapram, T. (2008) The association between obesity and the risk of cesarean delivery and other adverse pregnancy outcomes in singleton term pregnancies. Thai Journal of Obstetrics and Gynaecology, 16, 139-145.

[33] Cunningham, F.G., Leveno, K.J., Bloom, S.L., Hauth, J.C., Rouse, D.J. and Spong, C.Y. (2010) Williams obstetrics. 23rd Edition, Mc Graw-Hill, New York.

[34] Catalano, P.M. (2010) Obesity, insulin resistance, and pregnancy outcome. Reproduction, 140, 365-371. doi:10.1530/REP-10-0088

[35] Oteng-Ntim, E., Varma, R., Croker, H., Poston, L. and Doyle, P. (2012) Lifestyle interventions for overweight and obese pregnant women to improve pregnancy outcome: Systematic review and meta-analysis. BMC Medicine, 10, 47. doi:10.1186/1741-7015-10-47

[36] Gunderson, E.P. (2009) Childbearing and obesity in women: Weight before, during, and after pregnancy. Obstetrics \& Gynecology Clinics of North America, 36, 317332. doi:10.1016/i.ogc.2009.04.001

[37] Nitert, M.D., Foxcroft, K.F., Lust, K., Fagermo, N., Lawlor, D.A., O'Callaghan, M., et al. (2011) Overweight and obesity knowledge prior to pregnancy: A survey study. BMC Pregnancy Childbirth, 11, 96. doi:10.1186/1471-2393-11-96 